\title{
A Study on the Language Negative Transfer in Chinese Students' English Studies under the Background of "the Belt and Road"
}

\author{
Jinxiang Xue \\ School of Foreign Languages \\ Harbin University of Commerce \\ Harbin, China 150028
}

\begin{abstract}
The national strategy of China-" the Belt and Road" policy urges that colleges and universities should cultivate talents with excellent English, but language negative transfer may be a big hindrance against this goal. In second language acquisition, people hod different views on language transfer, and classified it into different types. Due to the differences between these Chinese and English, language negative transfer, does influence the Chinese students' English studies. Therefore, how to avoid language negative transfer in higher education will be conducive to the major construction, benefiting the cultivation of the higher-leveled talents, such as the postgraduates of language-oriented majors who are to be educated to better meet the requirements of the society and the country. In this process, participation in an English environment, and adopting a more advanced teaching and learning approach, etc. can be the key elements in the avoidance of language negative transfer in Chinese Students' English studies.
\end{abstract}

Keywords - language negative transfer; major construction; Chinese EFL learners; the Belt and Road

\section{INTRODUCTION}

The national policy of China " the Belt and Road" strategy urges that colleges and universities cultivate talents who are good at English in addition to their native language in order to meet the needs of the new era. However, Chinese EFL (English as a foreign language) learners always have problems that are attributable to language negative transfer.

The study of language transfer has been taking a dominant position in the field of Second Language Acquisition (SLA) since 1950s. Being regarded as one of the most important issues in applied linguistics, the origin of language transfer traces back to the behaviorist view-the first/native language (L1) habits influence the acquisition of the second/foreign language (L2) habits. Odlin [1] states that, "transfer is the influence resulting from the similarities and differences between the target language and the other languages that has been previously and perhaps imperfectly acquired". He further explores an original concept of transfer: in this case, a 'filter' that controls exactly what of the L2 input is retained by the learner. $\mathrm{He}$ also claims the reasonableness of accepting the notion of natural acquisition processes working together with language transfer processes. However, as a problematic term, "transfer" is to be seen as a general cover term for a number of different kinds of influence from languages other than the L2. Corder even suggests 'mother tongue influence' as a neutral and broader term to refer to the most widely accepted name 'transfer' [2].

\section{TYPES OF LANGUAGE TRANSFER}

Language transfer can be classified into different ways, and the following two are of the greatest popularity.

\section{A. Borrowing Transfer and Substratum Transfer}

Transfer can be classified into two types: borrowing transfer and substratum transfer. The former one refers to the influence a second language has on a previous acquired language (which is typically one's native language); and the latter one involves the influence of a source language (which is typically one's native language) on the acquisition of a target language (which is the second language no matter how many languages the learner already knows), which is the type of cross-linguistic influence investigated most in SLA [3].

A good example of borrowing transfer could be a native Chinese speaker's intonation and word stress could be influenced due to the learning and speaking of another language for a long time, especially in an immersion environment of the second or foreign language. With regard to substratum transfer, plenty of research on the influences of L1, such as in pronunciation, syntax, lexicon, etc., can provide lots of examples.

\section{B. Positive Transfer and Negative Transfer}

However, another kind of classification-positive transfer and negative transfer, is proposed by Selinker, according to the different influence that the L1 has on L2. Positive transfer occurs when a L1 form is used in the production of an L2 norm because of the same or similar feature shared by both the L1 and the L 2 norm. As mentioned by him, the facilitative effects can only be observed when learners with different native languages are investigated and learner comparisons are conducted. Negative transfer occurs when the $\mathrm{L} 1$ form used in $\mathrm{L} 2$ production is not a correct part of the 
L2 norm, which is also described as 'interference' by many researchers.

Negative language transfer, also termed as interference, hampers learning. In Odlin's view, negative transfer refers to cross-linguistic influences. In a broad sense, it is the transfer that leads to errors-underproduction, production, over production and misinterpretation, which constitute a divergence between the behavior of native transfer and nonnative speakers of language.

Underproduction errors means learners may produce very few or no examples of a target language. And overproduction is sometimes simply a consequence of underproduction. As for production errors, Odlin clarified that three types of errors are likely to arise from similarities and differences in the native and target languages: substitutions, calques, and alternations of structures. Misinterpretation refers native language structures can influence the interpretation of target language messages and sometimes that influence leads to learners inferring something very different from what speakers of the language would infer. And misinterpretation may also occur when native and target language word-order patterns differ or when cultures differ. [4]

\section{DIFFERENT VIEWS ON TRANSFER}

There are three main different views during the development of SLA: the behaviourist, the mentalist, and the interactionist. Pasty M. Lightbown proposed the similar ideas to account for SLA, suggesting 'innative view' to replace 'mentalist view' and regarding 'interactionist view' as a branch of cognitive theories. As the study of transfer is developing along with that of SLA, this paper classifies the different views on transfer into three categories: the behaviourist view, the innative view and the cognitive view. [5]

\section{A. The Behaviourist View}

Behaviourism intends to use habit formation to explain all the behavior in learning. With the belief that the native language has a significant influence on the success in L2 learning, Lado proposed a Contrastive Analysis Hypotheses $(\mathrm{CAH})$ in 1957, emphasizing that the L1 patterns and meanings affect a L2 learner's productive and receptive skills at both the linguistic and the cultural level. Therefore, it is predictable for linguists to find out the difficulty that a L2 leaner will meet in L2 learning, in terms of the contrastive analysis conducted between the L1 and L2 of the L2 learner. Lado's CAH contributes a lot to the study of transfer as well as L2 learning errors. [6]

\section{B. The Innative View}

In the late 1960s, the view of Behaviorism towards transfer has been challenged by a 'innative' view, which is based on the UG theory of Chomsky. Opposing to the early views on language transfer, Chomsky argues that children are born with an innative ability called language acquisition device (LAD), which arms them in language learning. Inspired by Chomsky's theory, Dulay and Burt put forward the 'L2=L1 hypothesis', which refers to the similarities between the children's acquisition of L1and L2. They also develop 'Creative Construction Hypothesis', stating the process in which children gradually reconstruct rules for speech they hear, with the instruction by universal innate mechanisms which make them formulate certain types of hypothesis about the language system being acquired until the mismatch between what they are exposed to and what they produce is resolved.

Based on these research, Dulay, Burt and Krashen claim that there is no difference between SLA and child native language acquisition, which shows the innative ability in language acquisition does exist. Due to the native language was regarded as an insignificant factor in SLA in this view, the study of language transfer was influenced negatively to some extent in this period. [7]

\section{The Cognitive View}

The research on language transfer stepped into a new stage-the cognitive period in the late 1970s. Gass claims that language transfer does indeed take place but some aspects of language are more likely to be transferred than others.

Some researchers argue that transfer should be regarded as much a creative process as any other part of acquisition. Schachter regards transfer as one 'strategy' which operates within a general process of hypothesis construction and testing, and L1 plays a role as 'learning strategy' in L2 learning. She further argues that the nature of transfer needs to be reconceptualized in line with this cognitive view of language: what enter into transfer phenomena are knowledge and mental representation. [8]

Moreover, the theory of interlanguage further develops the view on transfer, in which a learner is seen as an active participant who is testing and forming hypotheses in the process of creating an internalized system of how the target language works in the learning process.

\section{TRANSFER AND CHINESE EFL LEARNERS}

According to a lot of research on Chinese EFL learners, transfers occurred at all linguistic levels, phonetic, lexical, semantic and syntactic.

On the lexical level, some researchers studied the differences between Chinese and English in numerals. While others focused on the different using of reflexive pronoun 'self'. And there are also researchers who looked into the differences of the color terms in the two languages. Even some compared the lexis in the two languages in detail, according to the distribution of parts of speech, ratio of equivalents, and culture-loaded meanings.

On the syntactic level, it is presented that negation in Chinese and English were different at the level of phrase and sentence. In addition to the studies on the differences in terms of principles and parameters, some people looked into the differences in sentence group and sequence of sentences, having illustrated the influences of Chinese topicprominence structures on the learners' English.

Lots of research has also been done from cross-cultural aspect. Paulston discussed the significance in realizing 
cultural differences in language learning. Further, he proposed that difference of cultures should be kept in both EFL teachers' and learners' mind. To make Chinese learners aware of cultural differences, he studied the issue by citing words with cultural interpretations, and put effort in editing a reader on intercultural communication. [8]

In general, it is found out that Chinese-based language transfer were in the learners' interlanguage of English at the level of phonetics, morphology, semantics, syntax, and discourse patterns. Therefore, it is assumed that the so-called Chinglish does exist.

\section{SUGGESTIONS FOR CHINESE EFL LEARNERS}

To avoid the language negative transfer, some suggestions are proposed by the writer.

\section{A. Participation in An English Environment}

It has been found that Chinese students are worried about being laughed at when they answer the question wrongly. In addition, they don't like showing off their language skills among peers; Chinese students tend to use their mother tongue to do discussions quickly in class. Chinese learners are not very confident to speak up in front of strangers; they are worried about what other people think. This seems to be very similar to the importance of 'face' concept mentioned. On the other hand, students may feel less nervous to speak up in a familiar and welcome social group. [9] They feel much securely speaking English among the group which is already known.

As a consequence of the grammar- translation and the teacher-centred learning method, Chinese students' production skills are generally not as proficient as other skills. Hence, they may have limit achievements to learn a target language and have difficulty to use it; accordingly, they will be less motivated to participate in a target language classroom.

\section{B. On the Communicative Approach}

For many years, the communicative approach has been being used by teachers to teach Chinese learners. However, Chinese parents have high expectation on their children. The great educational expectation seems to run against with the traditional concepts and methods about language learning. Teacher's education nowadays tends to focus on the communicative approach with interaction, discussion and student-centred learning encouraged. This communicative approach is the main teaching method in the west; for Chinese learners, they may also feel the differences between the traditional method used in China and the method used in the west when they came to the English-speaking countries to study for the first time.

Even though the communicative approach is widely used in the classroom, both the advantages and disadvantages of using this method to teach Chinese learners should be considered.

Some Chinese students give some negative opinions on the communicative approach because they don't think it is an appropriate method to meet their needs, such as passing tests.
They think if the communicative approach is the only method used in the classrooms, the learning pace seems too slow to learn more contents.

Besides the negative opinions from Chinese students, some also find that the teachers in China think this method sometimes makes them embarrassed when they cannot answer the students' questions appropriately in the classroom. With the cultural gap between Western and Chinese culture, some Chinese students don't make much progress in learning from the communicative approach. In addition, a breakdown of language production and some disappointment are caused to the learners.

In contrast, others have found certain positive opinions from Chinese students. For example, the method is considered as an active learning way; it is useful to improve the oral performance in an examination; it raises classroom learning atmosphere and students' interest.

Above all, Anderson states that, 'the communicative methods are good for teaching Chinese who are about to go to English-speaking countries to live and study, but not for other Chinese students of English' [10]. In addition, on reflection it seemed that for the Chinese to adopt the approach proposed, they would not only have to do more of, better and perhaps a little differently, what they had always done, but they would also have to make radical changes to some of their basic beliefs, values and consequent ways of acting. Therefore, a more advanced teaching and learning approach should be proposed and adopted in cultivating Chinese students at all levels.

\section{CONCLUSION}

In general, not all learning can be considered with one factor. Certainly, learners would meet their learning targets when finding appropriate methods to improve their academic skills. Due to Chinese and English belong to two different language systems, their language usages and expressions sometimes are quite different. Owing to these differences, it is absolute for two peoples who come from different countries to make mistakes in English studies, and many of the mistakes are interfered by their mother tongue, so the role of one's mother tongue in English studies can not be ignored. In short, these mistakes are caused by the negative transfer from the mother tongue, so the study of negative transfer influences in business English writing has been drew wide attention.

A Chinese proverb says, 'Getting knowledge is just like drinking a cup of tea. The westerners try to let children feel thirsty and have a desire to drink tea but the Chinese education system just asks children to drink too much tea even when children don't feel thirsty'.[11] To compare the Western and Chinese language learning methods, researchers have found that the former tends to emphasize English language knowledge, content, teacher-centred classrooms and exam results; while the latter favors the skills and realistic use of language, student-centred classrooms and the process of learning.

Furthermore, people tend to adjust themselves to the environment. The learning difficulty would be overwhelmed 
through altering the mistakes in periods of time. [12] In addition, misunderstanding and differing expectations between cultures can result in one culture being referred to as 'problematic', 'deficient' and 'failing'. More understanding should be given on students' background, their learning way in classroom, and how they use the language through the learning experience and their views of the teaching methods. Trying to understand how these issues affect Chinese learners may help English teachers know better of their difficulty to meet the new expectation of this new era,[13] in particular, the new strategy " the Belt and Road" of China.

\section{ACKNOWLEDGMENT}

This research was financially supported by:

1. Teaching Reform and Teaching Research Program of Harbin University of Commerce: A Study on the Cultivation Module of Translation-Majored Masters Oriented by "the Belt and Road" Strategy (Grant No.: HSDJY027)

2. Philosophy and Social Sciences Research Program of Heilongjiang Province: A Study on Ecological Module of Business English Talents Developing in Heilongjiang Province (Grant No.: 15EDB01)

\section{REFERENCES}

[1] Odlin. T. Language Transfer: Cross-Linguistic Influence in Language Learning. Cambridge: Cambridge University Press, 2013.

[2] Corder, S. P. Error Analysis and Interlanguage. Oxford: Oxford University Press, 2001.

[3] Gass, S. and Selinker, L. Second Language Acquisition: an introductory course. Mahwah, HJ: LEA, chapter 3.2., 2011.

[4] Cook, Vivian. Second Language Learning and Language Teaching ( $3^{\text {rd }}$ ed.). London: Arnold, 2001.

[5] Dulay, H., Burt, M. and Krashen, S. Language Two. Oxford: Oxford University Press, 2015.

[6] Ellis, R. Understanding Second Language Acquisition. Oxford: Oxford University Press, 2015.

[7] Lightbown, P. M. and Spada, N. How Language are Learned. (Revised Edition). Oxford: Oxford University Press, 1999.

[8] Connor, U. Contrastive Rhetoric: cross-cultural aspects of secondlanguage writing. Cambridge: Cambridge University Press, 2006.

[9] Littlewood, W. Foreign and Second Language Learning. UK: Cambridge University Press, 2004.

[10] Liu, Shaozhong. Studies on Transfer in Second Language Acquisition. Guangxi Normal University Journal, 2001( 3):1-29.

[11] Larsen-Freeman, D. and Long, M. An Introduction to Second Language Acquisition Research. Harlow, UK: Longman, 2000.

[12] Leki, I. The preferences of ESL students for error correction in college-level writing classes. Foreign Language Annals, 2011 (24):203-18.

[13] Xue Jinxiang. A Study on the construction of curriculum of Business English Major from the Perspective of Ecology[J]. Heilongjiang Higher Education Research, 2013(2): 163-165. (in Chinese) 